\title{
Comparison of adsorption equilibrium of fructose, glucose and sucrose on potassium gel-type and macroporous sodium ion-exchange resins
}

\author{
C. Nobre ${ }^{\mathrm{a}, *}$, M.J. Santos ${ }^{\mathrm{a}}$, A. Dominguez ${ }^{\mathrm{a}}$, D. Torres ${ }^{\mathrm{a}, \mathrm{b}}, \mathrm{O}^{\mathrm{O}}$. Rocha ${ }^{\mathrm{b}}$, A.M. Peres ${ }^{\mathrm{c}}$, I. Rocha ${ }^{\mathrm{a}, \mathrm{b}}$, \\ E.C. Ferreira ${ }^{a}$, J.A. Teixeira ${ }^{a}$, L.R. Rodrigues ${ }^{a, b}$ \\ a IBB - Institute for Biotechnology and Bioengineering, Centre of Biological Engineering, University of Minho, Campus de Gualtar, 4710-057 Braga, Portugal \\ ${ }^{\mathrm{b}}$ Biotempo Lda., AVEPARK, Zona Industrial da Gandra, Apartado 4152, 4806-909 Caldas das Taipas, Portugal \\ c LSRE - Laboratory of Separation and Reaction Engineering, Escola Superior Agrária - Instituto Politécnico de Bragança, Quinta de Santa Apolónia, Apartado 172, \\ 5301-855 Bragança, Portugal
}

\section{A R T I C L E I N F O}

\section{Article history:}

Received 2 March 2009

Received in revised form 16 June 2009

Accepted 18 June 2009

Available online 23 June 2009

\section{Keywords:}

Adsorption isotherm

Macroporous resin

Gel-type resin

Cations

Sugars

\begin{abstract}
A B S T R A C T
Adsorption equilibrium of fructose, glucose and sucrose was evaluated on sulfonated poly(styrene-codivinylbenzene) cation-exchange resins. Two types of resins were used: potassium $\left(\mathrm{K}^{+}\right)$gel-type and sodium $\left(\mathrm{Na}^{+}\right)$macroporous resins. Influence of the cation and effect of the resin structure on adsorption were studied. The adsorption isotherms were determined by the static method in batch mode for monocomponent and multi-component sugar mixtures, at 25 and $40{ }^{\circ} \mathrm{C}$, in a range of concentrations between 5 and $250 \mathrm{~g} \mathrm{~L}^{-1}$. All adsorption isotherms were fitted by a linear model in this range of concentrations. Sugars were adsorbed in both resins by the following order: fructose $>$ glucose $>$ sucrose. Sucrose was more adsorbed in the $\mathrm{Na}^{+}$macroporous resin, glucose was identically adsorbed, and fructose was more adsorbed in the $\mathrm{K}^{+}$gel-type resin. Data obtained from the adsorption of multi-component mixtures as compared to the mono-component ones showed a competitive effect on the adsorption at $25^{\circ} \mathrm{C}$, and a synergetic effect at $40^{\circ} \mathrm{C}$. The temperature increase conducted to a decrease on the adsorption capacity for mono-component sugar mixtures, and to an increase for the multi-component mixtures. Based on the selectivity results, $\mathrm{K}^{+}$gel-type resin seems to be the best choice for the separation of fructose, glucose and sucrose, at $25^{\circ} \mathrm{C}$.
\end{abstract}

(C) 2009 Elsevier B.V. All rights reserved.

\section{Introduction}

Complex mixtures are frequently obtained when processes such as fermentative or enzymatic synthesis are used for sugar production. The application of these mixtures in the food industry requires their fractionation in order to meet final product specifications. Separation of glucose $(G)$ from fructose $(F)$ [1], sucrose $(\mathrm{S})$ in molasses [2,3] and fructose high-fructose corn syrups [4], represent major challenges in industrial sugar chromatographic separations. As adsorbents, ion exchange resins of sulfonated poly(styrene-co-divinylbenzene) (PS-DVB) have been largely used in the sugar industry due to their chemical inertness, higher capacity and selectivity $[5,8]$. According to their structure, the resins are classified in two major groups: gel-type and macroporous $[9,10]$.

Gel-type resins are translucent and have a smooth and uniform surface. These resins are highly swollen and have a low nominal degree of crosslinking (the DVB content is lower than 12\%) resulting in high water retention capacity and fast diffusion kinetics $[9,10]$.

\footnotetext{
* Corresponding author. Tel.: +351 253604 400; fax: +351253678986

E-mail address: clarissenobre@deb.uminho.pt (C. Nobre).
}

Therefore, they are soft and compressible, restricting their use in packed columns, particularly for large-scale applications as backpressure increases with the compression of the particles [9].

Macroporous resins are characterized by a permanent welldeveloped porous structure. They are opaque and their DVB content is greater than $20 \%$. Due to their high degree of crosslinking, they do not show shrinking problems and are resistant to degradation caused by osmotic shock and oxidation $[9,10]$.

These non-ionic resins can be functionalized with cations, usually calcium, potassium or sodium. These cations form complexes with the hydroxyl group of the adsorbed sugar, leading to a selective adsorption according to the orientation of the hydroxyl group. Thus, the conformation of the sugar and the cation determines the distribution coefficient and the cation-sugar affinity. The carbohydrates separation is mainly based on size exclusion, hydrophilic or hydrophobic interactions, ligand exchange and ion exchange [6,11,12].

Gel-type resins in calcium form are the most used in industrial separation of fructose from glucose due to the strong complexes that these resins form with fructose $[1,5,13]$. Several authors used calcium resins to fractionate mixtures of fructose, glucose and sucrose [14-16]. However, potassium $\left(\mathrm{K}^{+}\right)$and sodium $\left(\mathrm{Na}^{+}\right)$cations are the most recommended ions for the separation of these sugar 
Table 1

Physical and chemical properties of the resins.

\begin{tabular}{lll}
\hline $\begin{array}{l}\text { Physical and chemical } \\
\text { properties }^{\mathrm{a}}\end{array}$ & $\begin{array}{l}\text { Dowex } \\
\text { Monosphere } 88\end{array}$ & $\begin{array}{l}\text { Dowex Monosphere } \\
99 \mathrm{~K} / 320\end{array}$ \\
\hline $\begin{array}{ll}\text { Ionic form } \\
\text { Structure }\end{array}$ & $\mathrm{Na}^{+}$ & $\mathrm{K}^{+}$ \\
Matrix & Macroporous & Gel-type \\
Functional group & Styrene-DVB & Styrene-DVB \\
Total capacity $(\mathrm{eq} \mathrm{L}$ & Sulfonate \\
Water content & Sulfonate & $>1.5\left(\mathrm{H}^{+}\right.$form $)$ \\
Volume median diameter $(\mu \mathrm{m})$ & $>1.8$ & $57-61\left(\mathrm{H}^{+}\right.$form $)$ \\
\hline
\end{tabular}

a Data obtained from supplier.

mixtures due to their advantage in providing higher kinetic rates of adsorption [17,18].

The efficiency of a chromatographic process is largely dependent on the adsorbent used. Adsorption isotherms of the sugars present in a mixture are used for selecting the most adequate adsorbent to be used in the separation, since they describe the equilibrium distribution of a solute between the adsorbent and the liquid phase [19]. Thus, the evaluation of adsorption isotherms is extremely important as it represents the first step towards scaleup to industrial applications. Dynamic (frontal analysis [20]) and static (adsorption-desorption in column [20,21] and in batch mode $[15,22,23])$ methods have been used to determine the adsorption isotherms.

Parameters such as the structure of the resin, the ionic form $\left(\mathrm{Na}^{+}\right.$or $\mathrm{K}^{+}$), the components of the mixture (mono and multicomponent) and the temperature have been reported to largely influence the adsorption and separation of sugars. There are several studies concerning adsorption of fructose, glucose and sucrose in PS-DVB resins [20,22,23], however, none of these authors addressed all the referred parameters simultaneously. Thus, the aim of this work was to determine the adsorption isotherms of glucose, fructose and sucrose using two PS-DVB ion-exchange resins, namely a macroporous resin in $\mathrm{Na}^{+}$form, and a gel-type resin in $\mathrm{K}^{+}$form. A static method in batch mode was used to determine the adsorption parameters. Experiments were conducted with mono- and multi-component mixtures of sugars to evaluate competitiveness between the sugars present in the mixture. Temperature effect $(25$ and $40^{\circ} \mathrm{C}$ ) on adsorption and selectivity were also studied for both resins.

\section{Experimental}

\subsection{Materials}

A macroporous resin (Dowex Monosphere 88) in $\mathrm{Na}^{+}$form, and a gel-type resin in $\mathrm{K}^{+}$form (Dowex Monosphere 99K/320) were purchased from Supelco (Table 1).

Analytical grade fructose, glucose and sucrose were purchased from Panreac, Riedel-de Haën and Merck, respectively, and diluted in Milli-Q pure water.

\subsection{Determination of adsorption isotherms}

Adsorption equilibrium isotherms were determined using a static method, namely the adsorption-desorption in batch mode. Resins were washed several times with Milli-Q pure water until the liquid phase $\mathrm{pH}$ achieved a value of 6.0 , therefore avoiding further hydrolysis of sucrose. After equilibrium was reached, the resins were filtered to remove the water excess content. A volume of $3.5 \mathrm{~mL}$ of adsorbent, previously weighed, was placed into $15 \mathrm{~mL}$ Falcon tubes. Five Falcon tubes were dried at $105^{\circ} \mathrm{C}$ in order to determine the resin water content. Next, $3.5 \mathrm{~mL}$ of sugar solution was added to the resin and held for $8 \mathrm{~h}$ under agitation at 25 or $40^{\circ} \mathrm{C}$. Previous experiments demonstrated that $8 \mathrm{~h}$ were enough to reach the equilibrium without occurring sucrose hydrolysis (data not shown). These experiments were carried out in triplicate.

For determining the adsorption isotherms, mono- and multicomponent sugar solutions were prepared in a range of concentrations between 5 and $250 \mathrm{gL}^{-1}$. In all the multicomponent mixtures, individual sugars mass concentration was the same.

To ensure that the resin is ion saturated after each assay, a regeneration step was conducted with $\mathrm{Na}_{2} \mathrm{SO}_{4}$ and $\mathrm{K}_{2} \mathrm{SO}_{4}$, for the $\mathrm{Na}^{+}$ and $\mathrm{K}^{+}$resins, respectively. The amount of ions in solution was controlled by measuring the conductivity after each regeneration step.

\subsection{Sugars analysis}

Initial sugar mixture solutions and non-adsorbed sugar concentrations were determined by High-performance liquid chromatography (HPLC) using a Jasco device equipped with a refractive index detector. A Prevail Carbohydrate ES column $(5 \mu \mathrm{m}$, $250 \mathrm{~mm} \times 4.6 \mathrm{~mm}$ ) from Alltech was used. The mobile phase consisted of acetonitrile (HPLC Grade, from Carlo Erba) with $0.04 \%$ of ammonium hydroxide (HPLC Grade, from Sigma) in Milli-Q pure water $(70: 30, \mathrm{v} / \mathrm{v})$. Elution was conducted at a $1 \mathrm{~mL} \mathrm{~min}^{-1}$ flow rate and room temperature [24]. A Star Chromatography Workstation software (Varian) was used to record and integrate the refractive index responses.

\subsection{Adsorption parameters calculation}

Calculation of the equilibrium loading, $q$, is the first step to obtain the adsorption isotherms. Equilibrium loading was calculated for each tested concentration on both resins. The assays were performed for mono- and multi-component sugar mixtures at two different temperatures, namely 25 and $40^{\circ} \mathrm{C}$.

The equilibrium loading representing the mass of sugar adsorbed per mass of resin, is calculated from the following mass balance:

$q=\frac{\left(C_{\mathrm{i}}-C\right) V}{m}$

where $C_{\mathrm{i}}$ is the initial concentration of the sugar solution, with a volume $V$, added to a known amount of adsorbent $m$ and $C$ is the final concentration of sugars in equilibrium with the adsorbent.

The measured adsorption isotherm data were fitted using a linear regression equation:

$q=K . C$

allowing the determination of the distribution coefficient, $K$.

\subsection{Selectivity of the resin}

To evaluate the efficiency of sugars separation for each resin, at different conditions, the selectivity parameter $(\alpha)$ was calculated. For linear chromatography the selectivity can be expressed as the ratio between distribution coefficients of the sugars $j$ and $l$ [19].

$\alpha_{j / l}=\frac{K_{j}}{K_{l}}$

\subsection{Data analysis}

Linear regression models were used to fit the experimental data (Eq. (2)) and their significance was assessed using an ANOVA test. The quality of the fitted models was assessed by their $R$ square values. Significance of the slope was also determined by a $t$-test. The presence of outliers was investigated. Experimental 

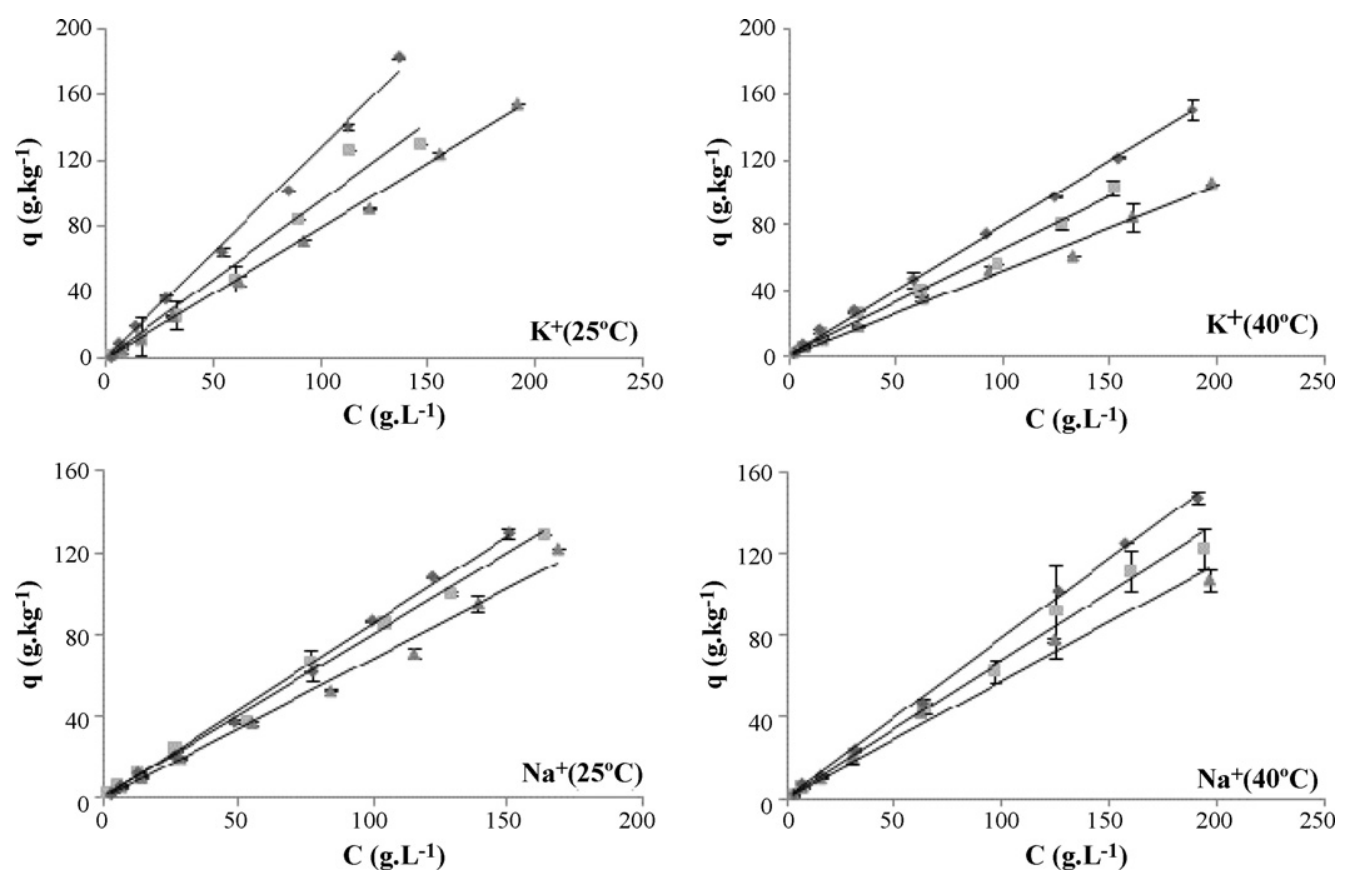

Fig. 1. Adsorption isotherms of $(\downarrow)$ fructose, $(\square)$ glucose and $(\Delta)$ sucrose on $\mathrm{Na}^{+}$macroporous and $\mathrm{K}^{+}$gel-type resins, at 25 and $40{ }^{\circ} \mathrm{C}$, with mono-component mixtures.

data showing standardized residual errors greater than 2.5 times the standard deviation were considered outliers. The normal distribution of the standardized residual errors, a pre-requisite of the linear regression model, was investigated using the ShapiroWilk test. Regression data were subjected to a likelihood ratio test of equality (covariance analysis) to determine if the slopes of each linear equation were the same. Statistic analyses were performed using the SPSS 17 Standard Version software (SPSS INC.). All statistical tests were conducted at a 5\% significance level.
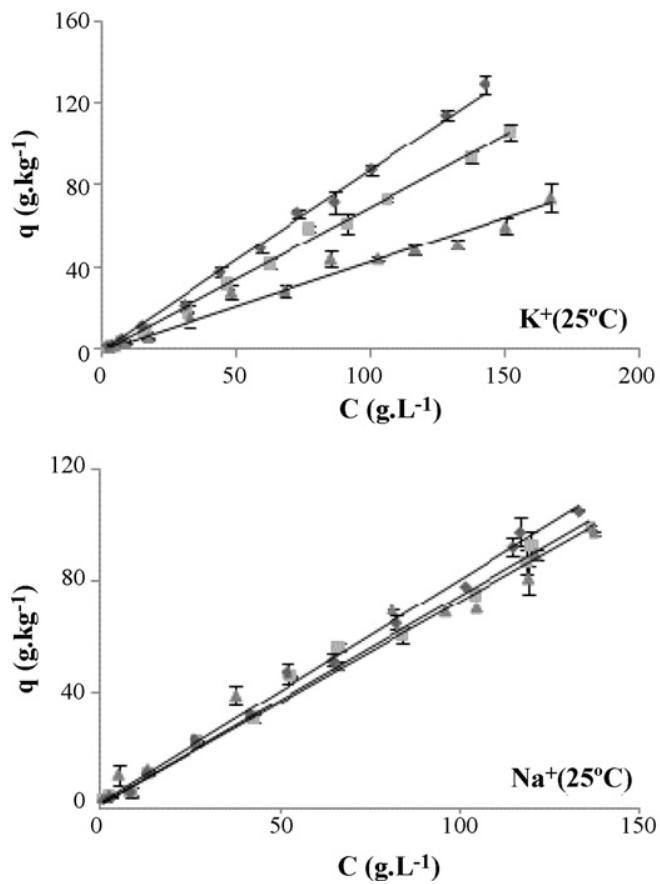

\section{Results and discussion}

\subsection{Adsorption isotherms}

As showed in Figs. 1 and 2, the adsorption isotherms, for fructose, glucose and sucrose for both mono- and multi-component mixtures, were appropriately fitted by linear regression models according to Eq. (2). These models were obtained after removing outliers and were found to be highly significant $(P<0.001)$. For all the adsorption isotherms $C$ was found to be a very significant
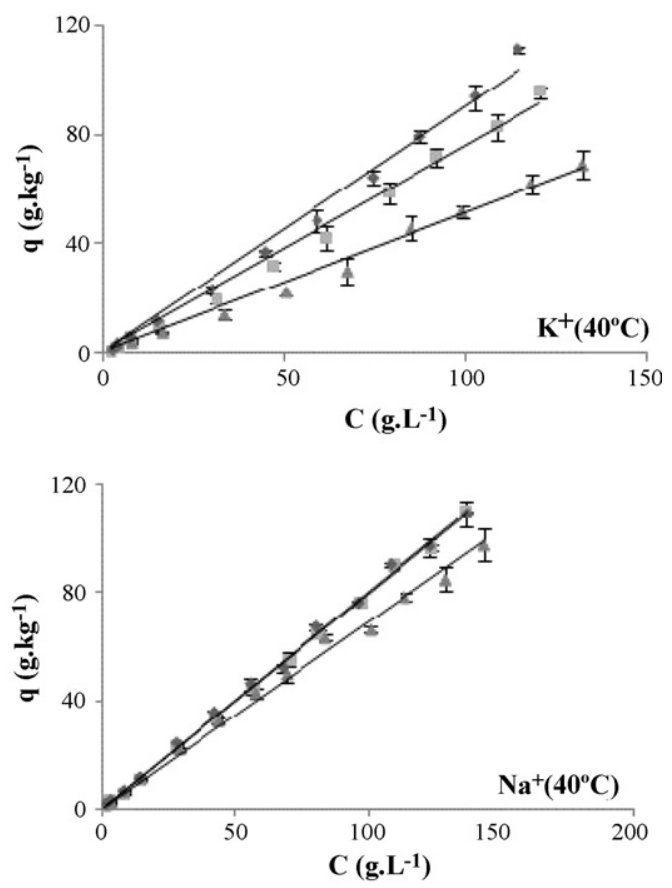

Fig. 2. Adsorption isotherms of $(\downarrow)$ fructose, $(\square)$ glucose and $(\Delta)$ sucrose on $\mathrm{Na}^{+}$macroporous and $\mathrm{K}^{+}$gel-type resins, at 25 and $40{ }^{\circ} \mathrm{C}$, with multi-component mixtures. 
Table 2

Distribution coefficients, $K\left(\mathrm{~L} \mathrm{~kg}^{-1}\right)$, for $\mathrm{Na}^{+}$macroporous and $\mathrm{K}^{+}$gel-type resins, using multi-component mixtures at 25 and $40^{\circ} \mathrm{C}$.

\begin{tabular}{|c|c|c|c|c|c|c|c|c|}
\hline & \multicolumn{4}{|l|}{$\mathrm{K}^{+}$} & \multicolumn{4}{|l|}{$\mathrm{Na}^{+}$} \\
\hline & $25^{\circ} \mathrm{C}$ & & $40^{\circ} \mathrm{C}$ & & $25^{\circ} \mathrm{C}$ & & $40^{\circ} \mathrm{C}$ & \\
\hline Fructose & $0.867 \pm 0.009$ & $R^{2}=0.996$ & $0.903 \pm 0.012$ & $R^{2}=0.995$ & $0.799 \pm 0.007$ & $R^{2}=0.997$ & $0.802 \pm 0.006$ & $R^{2}=0.998$ \\
\hline Glucose & $0.692 \pm 0.007$ & $R^{2}=0.997$ & $0.757 \pm 0.010$ & $R^{2}=0.994$ & $0.745 \pm 0.008$ & $R^{2}=0.996$ & $0.796 \pm 0.004$ & $R^{2}=0.999$ \\
\hline Sucrose & $0.429 \pm 0.009$ & $R^{2}=0.985$ & $0.511 \pm 0.008$ & $R^{2}=0.991$ & $0.726 \pm 0.013$ & $R^{2}=0.989$ & $0.691 \pm 0.007$ & $R^{2}=0.996$ \\
\hline
\end{tabular}

predictor $(P<0.001)$ being the interception values generally not statistically different from zero $(P>0.060)$, as theoretically expected. The linear models obtained explained the variability observed in the experimental $q$ values $\left(0.977 \leq R^{2} \leq 0.999\right)$. Moreover, in general, the residual errors associated to each linear model followed a normal distribution $(P>0.075)$, which is a pre-requirement of the linear regression models. Results obtained are in accordance with the general notions reported in the literature that low initial sugar concentrations conduct to linear adsorption isotherms $[5,25]$.

\subsection{Macroporous resin in sodium form versus gel-type resin in potassium form}

Potassium and sodium resins are considered non-complex ions, as it has been reported that sugars and univalent cations form weak complexes [7]. Therefore, for these resins the separation is performed due to the combination of size exclusion and restricted diffusion effects. This separation mechanism is advantageous since it provides higher adsorption kinetic rates as compared with the ones obtained with resins that form strong complexes with sugars, such as calcium resins [18].

In the $\mathrm{K}^{+}$and $\mathrm{Na}^{+}$resins, the water molecules held in the hydration sphere of the ions are exchanged with some hydroxyl groups of the sugars. Therefore, the number and orientation of the hydroxyl groups determine the relative adsorption of each sugar. The stability of the complex formed depends on the axial-equatorial (eq-ax) sequence of the hydroxyl groups. Glucose and fructose exist as pyranose and furanose ring structures with different mol percentages of $\alpha$ and $\beta$ forms. The $\beta$-D-glucose form does not have any eq-ax and $\alpha$-D-glucose has one. The $\alpha$-D-fructose has one eq-ax and $\beta$ D-fructose has two [26]. At temperatures between 25 and $40^{\circ} \mathrm{C}$, equilibrium composition for fructose is $10 \%$ of $\alpha$ form and $90 \%$ of $\beta$ [27]; and for glucose is $40 \%$ of $\alpha$ and $60 \%$ of $\beta$ [28]. Therefore, for these resins, fructose is expected to be much more adsorbed than glucose. Sucrose does not have any eq-ax oriented group and is excluded from the resin due to its higher molecular size.

The results of the covariance analysis (data not shown) showed that, for the multi-component sugar mixtures, the three sugars were adsorbed with different affinities $(P \leq 0.010)$ by both the $\mathrm{K}^{+}$ and $\mathrm{Na}^{+}$resins at 25 or $40^{\circ} \mathrm{C}$. Furthermore, as can be observed from Table 2, fructose was found to be the most adsorbed sugar, followed by glucose, and finally sucrose. An exception was found for the $\mathrm{Na}^{+}$resin at $40^{\circ} \mathrm{C}$, for which fructose and glucose showed similar adsorption rates ( $K$ equal to 0.802 and 0.796 , respectively, $P=0.848$ ) although higher than the ones found for sucrose ( $K$ equal to $0.691, P<0.001$ ).
For multi-component mixtures at $25^{\circ} \mathrm{C}$ (Table 2), glucose and mostly sucrose showed higher distribution coefficients for the $\mathrm{Na}^{+}$ than for the $\mathrm{K}^{+}$resin $(P \leq 0.037)$. At $40^{\circ} \mathrm{C}$, glucose showed the same adsorption affinity for both resins $(P=0.670)$ (Table 2$)$, and sucrose showed a higher adsorption affinity for the $\mathrm{Na}^{+}$resin $(P<0.001)$. On the other hand, fructose showed a lower adsorption affinity for the $\mathrm{Na}^{+}$resin for both temperatures studied $(P<0.001)$.

Gramblicka and Polakovic [23], studied recently the adsorption of sugar mixtures at $60^{\circ} \mathrm{C}$ using two $\mathrm{Na}^{+}$resins with different structures. These authors showed that sucrose adsorption in $\mathrm{Na}^{+}$ macroporous resin was higher than in $\mathrm{Na}^{+}$gel-type. Moreover, they found that glucose and fructose had the same adsorption affinities. Additionally, Vente et al. [15] studied sugars adsorption using two gel-type resins in $\mathrm{Na}^{+}$and $\mathrm{K}^{+}$forms at $60^{\circ} \mathrm{C}$. They reported a lower fructose and glucose adsorption in the $\mathrm{Na}^{+}$resin in comparison with the $\mathrm{K}^{+}$one. Therefore, the results obtained in this work at $40^{\circ} \mathrm{C}$ are in general in accordance with those reported in the studies described above.

In summary, sucrose adsorbed better in macroporous and $\mathrm{Na}^{+}$ resins, glucose showed the same adsorption in macroporous and gel-type resins, and fructose was found to have a higher adsorption in the $\mathrm{K}^{+}$gel-type resin.

\subsection{Mono- versus multi-component mixtures}

Assays using multi-component sugar mixtures were performed to evaluate sugars adsorption competitiveness. In general, a decrease in the adsorption loading was found for the sugars in both resins $(P \leq 0.034)$, when comparing results gathered in Table 2 with the results from experiments conducted with mono-component mixtures at $25^{\circ} \mathrm{C}$ (Table 3). An exception was found for sucrose in $\mathrm{Na}^{+}$resin, where similar results were obtained for mono- and multicomponent mixtures $(P=0.532)$. At $40^{\circ} \mathrm{C}$ the adsorption of each sugar present in the multi-component mixture was higher than the observed in the mono-component ones $(P \leq 0.019)$, except for sucrose in $\mathrm{K}^{+}$resin where a similar behavior was found $(P=0.463)$.

Nowak et al. [20] recently studied the competitiveness between fructose, glucose and sucrose by adding individual sugars to a mixture. These authors reported that the presence of additional sugars in solution increases the specific sugar loading. Their experiments were performed at higher temperatures, namely at 60 and $80^{\circ} \mathrm{C}$, and are in agreement with the results obtained at $40^{\circ} \mathrm{C}$ in the present work.

In summary, the results reported in the present study showed that at low temperatures, mixing sugars in the same proportion causes a decrease in the adsorption capacity of each sugar. Furthermore, a competitive effect in the sugars adsorption was found. On the other hand, high temperatures provided a reverse effect, and the

Table 3

Distribution coefficients, $K\left(\mathrm{~L} \mathrm{~kg}^{-1}\right)$, for $\mathrm{Na}^{+}$macroporous and $\mathrm{K}^{+}$gel-type resins, using mono-component mixtures at 25 and $40{ }^{\circ} \mathrm{C}$.

\begin{tabular}{|c|c|c|c|c|c|c|c|c|}
\hline & \multicolumn{4}{|l|}{$\mathrm{K}+$} & \multicolumn{4}{|l|}{$\mathrm{Na}+$} \\
\hline & $25^{\circ} \mathrm{C}$ & & $40^{\circ} \mathrm{C}$ & & $25^{\circ} \mathrm{C}$ & & $40^{\circ} \mathrm{C}$ & \\
\hline Fructose & $1.266 \pm 0.016$ & $\mathrm{R}^{2}=0.998$ & $0.794 \pm 0.006$ & $\mathrm{R}^{2}=0.999$ & $0.852 \pm 0.010$ & $R^{2}=0.998$ & $0.763 \pm 0.005$ & $\mathrm{R}^{2}=0.999$ \\
\hline Glucose & $0.923 \pm 0.031$ & $\mathrm{R}^{2}=0.986$ & $0.645 \pm 0.027$ & $\mathrm{R}^{2}=0.977$ & $0.793 \pm 0.011$ & $\mathrm{R}^{2}=0.997$ & $0.671 \pm 0.017$ & $\mathrm{R}^{2}=0.991$ \\
\hline Sucrose & $0.783 \pm 0.008$ & $\mathrm{R}^{2}=0.998$ & $0.529 \pm 0.010$ & $\mathrm{R}^{2}=0.995$ & $0.683 \pm 0.011$ & $\mathrm{R}^{2}=0.995$ & $0.576 \pm 0.013$ & $\mathrm{R}^{2}=0.993$ \\
\hline
\end{tabular}


Table 4

Selectivity values $(\alpha)$ for glucose, fructose, and sucrose, using $\mathrm{Na}^{+}$macroporous and $\mathrm{K}^{+}$gel-type resins.

\begin{tabular}{llllll}
\hline & $\mathrm{K}^{+}$ & & & $\mathrm{Na}^{+}$ & \\
\cline { 2 - 3 } & $25^{\circ} \mathrm{C}$ & $40^{\circ} \mathrm{C}$ & & $25^{\circ} \mathrm{C}$ & $40{ }^{\circ} \mathrm{C}$ \\
\hline $\mathrm{F} / \mathrm{G}$ & 1.25 & 1.18 & 1.07 & 1.01 \\
$\mathrm{G} / \mathrm{S}$ & 1.61 & 1.49 & 1.02 & 1.15 \\
$\mathrm{~F} / \mathrm{S}$ & 2.02 & 1.76 & 1.09 & 1.16 \\
\hline
\end{tabular}

presence of other sugars in the mixture conducted to an increase in the adsorption loading. Furthermore, a synergetic effect was found.

\subsection{Temperature effect}

Several authors reported that the use of temperatures above $70^{\circ} \mathrm{C}$ promotes a decrease of the liquid phase viscosity, an increase of the components solubility in the solvent, and microbial growth inhibition $[1,5,13]$. Despite these advantages, in the present study the temperatures used were 25 and $40^{\circ} \mathrm{C}$ because the maximum operating temperature for the $\mathrm{Na}^{+}$resin used was $40^{\circ} \mathrm{C}$, and the range of sugar concentrations studied was low.

Among the several phenomena that contribute to the adsorption mechanism of sugars in PS-DVB ion-exchange resins, the temperature dependence of the distribution coefficient is essentially attributable to complexation and adsorption. The contribution of temperature to the adsorption is correlated with the enthalpy term of the Van't Hoff equation. As a function of the variation of temperature, changes in retention can be caused either by variations in enthalpy or in entropy.

The adsorption capacity found for both resins, at 25 and $40^{\circ} \mathrm{C}$, showed that increasing the temperature promoted a decrease of the distribution coefficients for all the sugars studied in monocomponent mixtures (Table 3$)(P<0.001)$. These results are in agreement with the results obtained by Dendene et al. [25]. These authors compared the adsorption of sugars using $\mathrm{Na}^{+}$and $\mathrm{K}^{+}$geltype resins at different temperatures.

As verified by Pedruzzi et al. [18], the adsorption of sugars in PS-DVB resins leads to low values of enthalpy indicating that the adsorption is mainly physique, involving essential size-exclusion and ion-exclusion modes. In these cases, adsorption of sugars decreases at higher temperatures. The decrease of adsorption of chemically bonded sugars is most probably caused by weakening binding forces between the sugar and the resin [20].

Nevertheless, for the $\mathrm{Na}^{+}$resin the adsorptions of fructose and sucrose in multi-component mixtures were not significantly affected by the temperature $(P \geq 0.866)$, and for glucose an increase on the adsorption was observed $(P<0.001)$. Regarding the $\mathrm{K}^{+}$resin, a temperature increase resulted in an increase of the adsorption for all the sugars $(P \leq 0.012)$. These results showed that, for $\mathrm{K}^{+}$gel-type and $\mathrm{Na}^{+}$macroporous resins, increasing the temperature conducted to a higher sugar adsorption for multi-component mixtures.

Studies using multi-component adsorption of sugars are scarce. The work done by Nowak et al. [20] showed no temperature dependency of the distribution coefficient for glucose and sucrose, and a decrease of the adsorption of fructose was found when increasing the temperature. However, Best et al. [13] showed an increase of glucose adsorption as a result of the temperature increase.

The ion form of the resin, the DVB content and the sugars present in the mixtures seem to have a great influence on the adsorption behavior. In the present study, for $\mathrm{Na}^{+}$resin, the adsorption was found to be independent of the temperature, suggesting that this is an entropically determined process rather than enthalpic. However, for $\mathrm{K}^{+}$resin, the results showed higher adsorption for higher temperatures probably due to complexation with the cation.

\subsection{Selectivity}

Resin selectivity is a relevant parameter that should be considered whenever selecting the best resin for a certain separation. In the present study, the selectivities were calculated using the distribution coefficients obtained previously for multi-component mixtures at 25 and $40^{\circ} \mathrm{C}$ (Table 2) and are presented in Table 4 . The lowest selectivity was found for fructose/glucose since these sugars have the same molecular weight. Furthermore, the higher selectivity was found for fructose/sucrose due to the strong fructose adsorption onto the resins. These behaviors were found for both resins studied regardless of the temperature used.

Higher temperatures favored a decrease of the selectivity for the $\mathrm{K}^{+}$resin. However, for the $\mathrm{Na}^{+}$resin, the selectivity seemed to have not been affected by temperature.

In this work, the selectivity values found for $\mathrm{K}^{+}$gel-type resin were higher than for the $\mathrm{Na}^{+}$macroporous resin. These results are in accordance with the work of Gramblicka and Polakovic [23] that reported higher selectivity values when working with gel-type resins. Also, Vente et al. [15] found higher selectivity values for $\mathrm{K}^{+}$ gel-type resins as compared to $\mathrm{Na}^{+}$ones.

\section{Conclusions}

Fructose, glucose and sucrose adsorption isotherms, determined by the static method in batch mode, for $\mathrm{Na}^{+}$macroporous and $\mathrm{K}^{+}$ gel-type resins, showed linearity for the range of sugar concentrations used. Fructose was found to be the most adsorbed sugar in both resins, followed by glucose and finally sucrose.

Comparing the adsorption of each sugar present in a multicomponent mixture, it was found that sucrose was more adsorbed in the $\mathrm{Na}^{+}$macroporous resin; glucose showed almost the same adsorption in both resins; and fructose was more adsorbed in $\mathrm{K}^{+}$ gel-type resin.

A competitive effect on the adsorption was found at $25^{\circ} \mathrm{C}$ for the multi-component mixtures as compared to the mono-component ones. However, a reverse effect was found at $40^{\circ} \mathrm{C}$, therefore a synergetic adsorption of sugars in mixtures of multi-components was observed.

The temperature increase conducted to a decrease in the adsorption for mono-component sugar mixtures. However, for multi-component sugar mixtures the temperature increase conducted to an increase of the adsorptions.

Finally, the values of selectivity obtained for $\mathrm{K}^{+}$gel-type showed that this resin is probably the best choice to separate mixtures of fructose, glucose and sucrose, operating at $25^{\circ} \mathrm{C}$.

\section{Acknowledgment}

The first author gratefully acknowledges to Fundação para a Ciência e a Tecnologia (Portugal) for the PhD Grant received (reference SFRH/BD/32514/2006).

\section{References}

[1] D.C.S. Azevedo, A.E. Rodrigues, Fructose-glucose separation in a SMB pilot unit: modeling, simulation, design, and operation, AIChe J. 47 (2001) 2042-2051.

[2] L.G. Lefevre, Separation of fructose from glucose using cation exchange resin salts, U.S. Patent 3,044,905 (1962).

[3] R.W. Neuzil, R.L. Fergin, Extraction of sucrose from molasses, U.S. Patent $14,333,770$ (1982).

[4] A. Toumi, S. Engell, Optimization-based control of a reactive simulated moving bed process for glucose isomerization, Chem. Eng. Sci. 59 (2004) 3777-3792.

[5] D.A. Luz, A.K.O. Rodrigues, F.R.C. Silva, A.E.B. Torres, C.L. Cavalcante, E.S. Brito, D.C.S. Azevedo, Adsorptive separation of fructose and glucose from an agroindustrial waste of cashew industry, Bioresour. Technol. 99 (2008) 2455-2465.

[6] M. Stefansson, D. Westerlund, Ligand-exchange chromatography of carbohydrates and glycoconjugates, J. Chromatogr. A 720 (1996) 127-136. 
[7] J. Tiihonen, I. Markkanen, E. Paatero, Complex stability of sugars and sugar alcohols with $\mathrm{Na}^{+}, \mathrm{Ca}^{2+}$, and $\mathrm{La}^{3+}$ in chromatographic separations using poly(styrene-co-divinylbenzene) resins and aqueous organic eluents, Chem. Eng. Commun. 189 (2002) 995-1008.

[8] T. Okada, Multifunctional separation with polyamine-bonded resin, Anal. Chim. Acta 303 (1995) 193-197.

[9] D.C. Sherrington, Preparation, structure and morphology of polymer supports, Chem. Commun. 21 (1998) 2275-2286.

[10] I.M. Abrams, J.R. Millar, A history of the origin and development of macroporous ion-exchange resins, React. Funct. Polym. 35 (1997) 7-22.

[11] S.C. Churms, Recent progress in carbohydrate separation by high-performance liquid chromatography based on size exclusion, J. Chromatogr. A 720 (1996) $151-166$.

[12] S.C. Churms, Recent progress in carbohydrate separation by high-performance liquid chromatography based on hydrophilic interaction, J. Chromatogr. A 720 (1996) 75-91.

[13] Y.A. Beste, M. Lisso, G. Wozny, W. Arlt, Optimization of simulated moving bed plants with low efficient stationary phases: separation of fructose and glucose, J. Chromatogr. A 868 (2000) 169-188.

[14] A.J. Howard, G. Carta, C.H. Byers, Separation of sugars by continuous annular chromatography, Ind. Eng. Chem. Res. 27 (1988) 18731882.

[15] J.A. Vente, H. Bosch, A.B. de Haan, P.J.T. Bussmann, Comparison of sorption isotherms of mono- and disaccharides relevant to oligosaccharide separations for $\mathrm{Na}, \mathrm{K}$, and Ca loaded cation exchange resins, Chem. Eng. Commun. 192 (2005) 23-33.

[16] P.E. Barker, G. Ganetsos, J. Ajongwen, A. Akintoye, Bioreaction separation on continuous chromatographic systems, Chem. Eng. J. Biochem. Eng. J. 50 (1992) B23-B28.

[17] M.C.D. Paillat, Different industrial applications of continuous chromatography in the sugar industry and for the production of sugar derivatives, Detmold Starch Convention (1999).
[18] I. Pedruzzi, E.A.B. da Silva, A.E. Rodrigues, Selection of resins, equilibrium and sorption kinetics of lactobionic acid, fructose, lactose and sorbitol, Sep. Purif. Technol. 63 (2008) 600-611.

[19] A.E.M. Schulte, Fundamentals and general terminology, in: Schmidt-Traub (Ed.), Preparative Chromatography of Fine Chemicals and Pharmaceutical Agents, Wiley-VCH, Weinheim, 2005, pp. 32-40.

[20] J. Nowak, K. Gedicke, D. Antos, W. Piatkowski, A. Seidel-Morgenstern, Synergistic effects in competitive adsorption of carbohydrates on an ion-exchange resin, J. Chromatogr. A 1164 (2007) 224-234.

[21] D.C.S. Azevedo, A. Rodrigues, Obtainment of high-fructose solutions from cashew (Anacardium occidentale) apple juice by simulated moving-bed chromatography, Sep. Sci. Technol. 35 (2000) 2561-2581.

[22] J.A. Vente, H. Bosch, A.B. de Haan, P.J.T. Bussmann, Evaluation of sugar sorption isotherm measurement by frontal analysis under industrial processing conditions, J. Chromatogr. A 1066 (2005) 71-79.

[23] M. Gramblicka, M. Polakovic, Adsorption equilibria of glucose, fructose, sucrose, and fructooligosaccharides on cation exchange resins, J. Chem. Eng. Data 52 (2007) 345-350.

[24] L.G. Dias, A.C.A. Veloso, D.M. Correia, O. Rocha, D. Torres, I. Rocha, L.R. Rodrigues, A.M. Peres, UV spectrophotometry method for the monitoring of galactooligosaccharides production, Food Chem. 113 (2009) 246-252.

[25] K. Dendene, L. Guihard, B. Balannec, B. Bariou, Study of the separation of lactose lactulose and galactose by liquid-chromatography using cationic ion-exchange resin columns, Chromatographia 41 (1995) 561-567.

[26] R.W. Goulding, Liquid-chromatography of sugars and related polyhydric alcohols on cation exchangers - effect of cation variation, J. Chromatogr. 103 (1975) 229-239.

[27] F.W. Lichtenthaler, S. Ronninger, Alpha-D-glucopyranosyl-D-fructoses - distribution of furanoid and pyranoid tautomers in water, dimethyl-sulfoxide, and pyridine - studies on ketoses, 4, J. Chem. Soc., Perkin Trans. 2 (1990) 1489-1497.

[28] S.J. Angyal, The composition of reducing sugars in solution - current aspects, Carbohyd. Chem. Biochem. 49 (1991) 19-35. 